\title{
The Use of Candida pyralidae and Pichia kluyveri to Control Spoilage Microorganisms of Raw Fruits Used for Beverage Production
}

\author{
Maxwell Mewa-Ngongang 1,2,*(D), Heinrich W. du Plessis ${ }^{1}\left(\mathbb{D}\right.$, Seteno Karabo Obed Ntwampe ${ }^{2,3}(\mathbb{D}$,

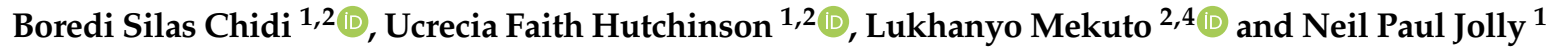 \\ 1 PostHarvest and Agro-Processing Technologies, ARC Infruitec-Nietvoorbij (The Fruit, Vine and Wine \\ Institute of the Agricultural Research Council), Private Bag X5026, Stellenbosch 7599, South Africa; \\ DPlessisHe@arc.agric.za (H.W.d.P.); boredi2002@gmail.com (B.S.C.); HutchinsonU@arc.agric.za (U.F.H.); \\ JollyN@arc.agric.za (N.P.J.) \\ 2 Bioresource Engineering Research Group (BioERG), Department of Biotechnology, Cape Peninsula \\ University of Technology, P.O. Box 652, Cape Town 8000, South Africa; NtwampeS@cput.ac.za (S.K.O.N.); \\ lukhayo.mekuto@gmail.com (L.M.) \\ 3 Department of Chemical Engineering, Cape Peninsula University of Technology, P.O. Box 652, Cape Town \\ 8000, South Africa \\ 4 Department of Chemical Engineering, University of Johannesburg, PO Box 17011, Johannesburg 2028, \\ Gauteng, South Africa \\ * Correspondence: mewam@arc.agric.za; Tel.: +27-(0)-21-809-3442
}

Received: 12 August 2019; Accepted: 24 September 2019; Published: 6 October 2019

\begin{abstract}
Undesired fermentation of fruit-derived beverages by fungal, yeast and bacterial spoilage organisms are among the major contributors of product losses in the food industry. As an alternative to chemical preservatives, the use of Candida pyralidae and Pichia kluyveri was assessed for antimicrobial activity against several yeasts (Dekkera bruxellensis, Dekkera anomala, Zygosaccharomyces bailii) and fungi (Botrytis cinerea, Colletotrichum acutatum and Rhizopus stolonifer) associated with spoilage of fruit and fruit-derived beverages. The antagonistic properties of C. pyralidae and P. kluyveri were evaluated on cheap solidified medium (grape pomace extract) as well as on fruits (grapes and apples). Volatile organic compounds (VOCs) from C. pyralidae and P. kluyveri deemed to have antimicrobial activity were identified by gas chromatography-mass spectrometry (GC-MS). A cell suspension of C. pyralidae and P. kluyveri showed growth inhibition activity against all spoilage microorganisms studied. Direct contact and extracellular VOCs were two of the mechanisms of inhibition. Twenty-five VOCs belonging to the categories of alcohols, organic acids and esters were identified as potential sources for the biocontrol activity observed in this study. This study reports, for the first time, the ability of $C$. pyralidae to inhibit fungal growth and also for P. kluyveri to show growth inhibition activity against spoilage organisms $(n=6)$ in a single study.
\end{abstract}

Keywords: biopreservation compounds; Candida pyralidae; Pichia kluyveri; biological control; volatile organic compounds

\section{Introduction}

Fruit and fruit-derived beverages are important nutritional and economically viable commodities. They also provide vitamins and some essential minerals in the human diet. However, fruit losses caused by spoilage fungi pose numerous challenges to the agrifood industry [1,2]. Additionally, the shortened shelf-life of fruit caused by microbial spoilage is a factor that negatively affects the market value and processing of fruit. It has long been known that fungal spoilage organisms can 
contaminate agricultural produce before, during and after harvest, as well as during transportation and processing [3-6]. During postharvest handling, about $25 \%$ of the total harvested fruit is lost due to spoilage fungi [7-10], which is an amount of food that can feed millions of households worldwide. Spoilage organisms, i.e., Botrytis cinerea, Colletotricum acutatum and Rhizopus stolonifer, causes losses in more than 200 crop species [11,12]. Mycotoxins are secondary metabolites of fungi toxic to animals and humans [13]. The most important fungal genera producing mycotoxins that are found in food products are Aspergillus, Fusarium, Alternaria and Penicillium [14,15]. The components of fruit and fruit-derived beverages, i.e., sugar content, macro- and micro-nutrients, are conducive to microbial proliferation and therefore, prone to microbial spoilage. As a health risk and mode of infection, the patulin producing strain such as Penicillium expansum has been published as one of the most serious postharvest contaminant of apple and derived juices $[13,16]$. Although the presence of some mycotoxin is almost unavoidable, there are set limits, deemed safe for consumption, that are allowed on raw fruits and the derived beverages [16-19]. Even if there are safe limits for mycotoxins in fruits and the derived beverages, it is imperative to combat contamination caused by fungi in order to ensure that toxic level of contamination is avoided as this can be lethal to consumers. Other spoilage microorganisms such as Dekkera bruxellensis, Dekkera anomala and Zygosaccharomyces bailii are known to be responsible for spoilage and product losses in the beverage industry [20-22]. To minimise such losses, synthetic chemicals are currently being used for controlling microbial spoilage, but their continued use as postharvest control agents of fruit or as preservatives, raises human health concerns. As a result, the eradication of these chemicals and the development of safer alternatives is now a priority in fruit and beverage industries, i.e., agro-processing and retail industries [8,23-25].

As an alternative to synthetic chemicals, the antagonistic mechanisms of yeasts against fruit and beverage spoilage microorganisms have been investigated [11,26-28]. Several antagonistic characteristics are associated with the ability of the yeasts to rapidly reproduce on simple nutrients and to colonise surfaces, while competing for nutrients and space with the other flora $[29,30]$, and the induction of host resistance for some yeasts [31-33] and the ability of yeasts to produce cell wall degrading enzymes such as laminarinases, glucanases, proteases, peroxidase and chitinases [33-36]. Other antagonistic mechanisms can be attributed to the effect of decreasing germ tube length, preventing mycelial growth and suppressing conidial germination [37], the parasitism being associated with the release of hydrolase, the oxidative stress [33] as well as the spoilage fungi and growth inhibition by diffusible volatile organic compounds (VOCs) [38-41] in synergy with a carbon dioxide enclosed environment [42]. Species of C. pyralidae have previously been studied as producers of killer toxins which can act against beverage spoilage organisms [43]. However, many have not yet been explored as potential biocontrol agents against fruit-spoilage organisms. Similarly, P. kluyveri has also been determined as an antagonistic yeast for biocontrol applications $[44,45]$.

Therefore, the aim of this study was to explore whether C. pyralidae and P. kluyveri strains can control the growth of beverage spoilage yeasts and fungi contaminating fruits used for beverage production.

\section{Materials and Methods}

\subsection{Microorganisms and Culture Conditions}

The yeasts C. pyralidae (Y1117, isolated from grape must), P. kluyveri (Y1125, isolated from Sclerocarya birrea juice) and the beverage spoilage yeasts D. bruxellensis (ISA 1653), D. anomala (MSB/1) and Z. bailii (Y0070) were obtained from the ARC Infruitec-Nietvoorbij culture collection (Stellenbosch, South Africa). Furthermore, spoilage and disease causing fungi in the South African fruit industry, $B$. cinerea, C. acutatum and R. stolonifer, were obtained from the postharvest control laboratory at ARC Infruitec-Nietvoorbij (Stellenbosch). C. pyralidae and P. kluyveri cells were prepared by transferring a wire loop full of each culture into a test tube containing $5 \mathrm{~mL}$ of Yeast Peptone Dextrose (YPD) broth (Sigma Aldrich, Darmstadt, Germany) and incubated at $28{ }^{\circ} \mathrm{C}$ for $24 \mathrm{~h}$. Spoilage yeast suspensions (D. bruxellensis, D. anomala, and Z. bailii) were prepared using YPD (Sigma Aldrich, 
Darmstadt, Germany) broth for $24 \mathrm{~h}$ at $28^{\circ} \mathrm{C}$. Cells were recovered by centrifugation at $10,000 \mathrm{rpm}$ for $10 \mathrm{~min}$. A haemocytometer and a microscope (400× magnification) were used to count the yeast cells and fungal spores before all mother spore solutions were diluted to the desired concentration of $10^{5}$ spores $\mathrm{mL}^{-1}[46]$.

Grape pomace from semi-industrial, conventional Chenin blanc wine grapes was obtained from the ARC Infruitec-Nietvoobij research cellar (Stellenbosch) and pressed at $200 \mathrm{kPa}$. The resultant grape pomace extract was frozen in polypropylene buckets at $-10{ }^{\circ} \mathrm{C}$. Prior to use, the grape pomace extract was thawed and diluted with sterile distilled water to the required sugar concentration $(50,100$, 150 and $200 \mathrm{~g} \mathrm{~L}^{-1}$ ) and the final concentrations of the yeast assimilable nitrogen (YAN) were 0.045 , 0.074, 0.136 and $0.185 \mathrm{~g} \mathrm{~L}^{-1}$, respectively (Arena 20XT, Thermo Fischer Scientific, Vantaa, Finland). The grape pomace extract was adjusted to $\mathrm{pH} 5$, using $0.1 \mathrm{M} \mathrm{NaOH}$ prior to use. Bacteriological agar (Biolab, Merck, South Africa) was added at $10 \mathrm{~g} \mathrm{~L}^{-1}$ and autoclaved at $121{ }^{\circ} \mathrm{C}$ for $20 \mathrm{~min}$ and subsequently supplemented with $0.1 \mathrm{~g} \mathrm{~L}^{-1}$ chloramphenicol (Sigma-Aldrich, Darmstadt, Germany) to prevent bacterial growth. This grape pomace extract agar (GPA) was used for growth inhibition assays and grape pomace extract broth (GPB) was used as a fermentation medium.

From the 24-h-old yeast cultures, $1 \mathrm{~mL}$ of $C$. pyralidae and P. kluyveri containing broth was transferred to $150 \mathrm{~mL}$ sterile grape pomace extract broth (GPB) subsequent to incubation at $23^{\circ} \mathrm{C}$ and agitated at $150 \mathrm{rpm}$, using a rotary shaker (LM-53OR, RKC Instrument Inc., Ohta-ku Tokyo, Japan) for

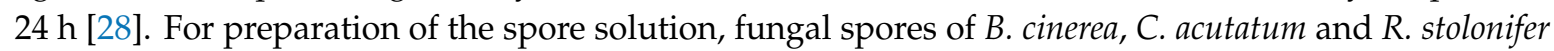
were obtained from 14 day old fungal plates incubated at $20^{\circ} \mathrm{C}$. The spores were harvested by gently scrapping-off the surface with a sterile wire loop and subsequent to rinsing $(n=3)$ with sterile distilled water to obtain a $100 \mathrm{~mL}$ spore solution in $250 \mathrm{~mL}$ Schott bottles. Similarly, $5 \mathrm{~mm}$ diameter mycelia disks of each fungus were cut from 5-day old plates also grown on GPA at $20^{\circ} \mathrm{C}$.

\subsection{Effect of C. pyralidae and P. kluyveri on Spoilage Yeasts}

\subsubsection{Growth Inhibition Assay}

The growth inhibition assay as described by Mehlomakulu et al. [43] was used. The seeding procedures as described by Mewa-Ngongang et al. [28,43] and Mehlomakulu et al. [43] were applied. The GPA plates were seeded with $10^{6}$ cells $\mathrm{mL}^{-1}$ of D. bruxellensis, D. anomala or Z. bailii, respectively. C. pyralidae and P. kluyveri cells were adjusted to a concentration of $10^{8}$ cells $\mathrm{mL}^{-1}$, as described by Qin et al. [46], and $10 \mu \mathrm{L}$ of each culture was spotted onto GPA plates seeded with D. bruxellensis, D. anomala or Z. bailii, respectively. After $72 \mathrm{~h}$ of incubation at $20^{\circ} \mathrm{C}$, the plates were inspected for zone of inhibition as shown by the formation of a clear zone around the yeast colonies.

\subsubsection{Production of Biopreservation Compounds Using Grape Pomace Extract Broth}

The diluted GPB $\left(100,150\right.$ and $\left.200 \mathrm{~g} \mathrm{~L}^{-1}\right)$ was autoclaved for $20 \mathrm{~min}$ at $121^{\circ} \mathrm{C}$, cooled and was used for the production of the crude biopreservation compounds. C. pyralidae and P. kluyveri was inoculated at a concentration of $10^{6}$ cells $\mathrm{mL}^{-1}$. After initial inoculation $(\mathrm{t}=0 \mathrm{~h})$, samples $(2 \mathrm{~mL})$ were taken every $4 \mathrm{~h}$ for the duration of the experiment, which lasted for $24 \mathrm{~h}$. In total, samples $(n=6)$ were taken per yeast treatment and each treatment had three replicates. Each sample was centrifuged at $10,000 \mathrm{rpm}$, and the supernatant was tested for growth inhibition activity to determine the time in the fermentation cycle at which maximum growth inhibition activity could be obtained.

\subsection{Effect of C. pyralidae and P. kluyveri on Fungal Growth}

\subsubsection{Fungal Spore Germination Assay}

A radial inhibition assay was conducted using the agar plate method as described by Núñez et al. [47]. Yeast (C. pyralidae and P. kluyveri) cell suspensions $\left(1 \times 10^{8}\right.$ cells $\left.\mathrm{mL}^{-1}\right)$ were prepared from the yeast culture broths and a fungal spore suspension of $10^{5}$ spores $\mathrm{mL}^{-1}$ was prepared from the mother solution. 
A volume $(100 \mu \mathrm{L})$ of yeast was spread-plated on GPA and dried. Subsequently, $10 \mu \mathrm{L}$ of $10^{5}$ spores $\mathrm{mL}^{-1}$ of each fungus was spotted at the centre of the plate with each treatment having three replicates. For the negative control plates, only $10 \mu \mathrm{L}$ of the spore solution $\left(10^{5}\right.$ spores $\left.\mathrm{mL}^{-1}\right)$ were spotted at the centre of the GPA. The plates were then incubated at $15^{\circ} \mathrm{C}$ for 7 days. The fungal radial inhibition (FRI) was calculated using the mathematical expression: $F R I=\left(D_{0}-D_{t} / D_{0}\right) \times 100$, with $D_{0}$ representing the average diameter of the fungal colony on the negative control plates and $D_{t}$ representing the diameter of the fungal colony on the yeast treated plates [47].

\subsubsection{The Mouth-to-Mouth Assay and Volatile Organic Compounds (VOCs) Activity}

The mouth-to-mouth assay as described by Medina-Córdova et al. [48] was used and repeated twice. Once, to study yeast inhibition and secondly, to investigate fungal growth inhibition. Two GPA plates (facing each other) were used, with the bottom plate being spread-plated with a $100 \mu \mathrm{L}$ of the yeast suspension $\left(10^{8}\right.$ cell $\left.\mathrm{mL}^{-1}\right)$, while the top plate (cover) contained a $5 \mathrm{~mm}$ mycelial disk at the centre. The negative control plates were only seeded with a $5 \mathrm{~mm}$ diameter mycelial disk (no yeast treatment in the bottom plate). All plates (in triplicates) were sealed with laboratory film and incubated at $15{ }^{\circ} \mathrm{C}$ for 7 days. The volatile organic compounds (VOCs) inhibition activity (VOCIA) was calculated as described by the mathematical expression used for FRI (Section 2.3.1).

\subsection{In Vivo Studies: Postharvest Efficacy of C. pyralidae and P. kluyveri in Controlling Fruit-Spoilage}

\subsubsection{Apple Bioassays}

Postharvest biocontrol efficacy assays were performed on "Golden Delicious" apples (Malus domestica). Nine treatments were investigated, each having 10 replicates. Ethanol $(70 \% \mathrm{v} / \mathrm{v})$ was sprayed on the fruits and allowed to dry completely before wound infliction. Apples were uniformly wounded with a sterile cork borer (approximately $5 \mathrm{~mm}$ diameter and $3 \mathrm{~mm}$ deep). After $15 \mathrm{~min}$, $15 \mu \mathrm{L}$ of a yeast inoculum $\left(10^{8}\right.$ cell $\left.\mathrm{mL}^{-1}\right)$ was introduced into the wound and then allowed to dry for $30 \mathrm{~min}$. Subsequently, $15 \mu \mathrm{L}$ of the spore suspension $\left(10^{5}\right.$ spores $\left.\mathrm{mL}^{-1}\right)$ was introduced into the wound. Treated fruits were maintained at $-0.5^{\circ} \mathrm{C}$ for 4 weeks in a tightly closed container, and then stored at $20^{\circ} \mathrm{C}$ for 7 days, to simulate shipping and shelf-life conditions, respectively, in a commercial setting. The containers were sterilised prior to use and were tightly closed in order to entrap the VOCs in the airspace and to observe the VOCs effect similar to the in vitro plate assay. The biocontrol efficacy was evaluated by comparing the decay diameter of the negative control to those of the treated apples using the FRI. Negative controls were prepared by inoculating fruits with $15 \mu \mathrm{L}$ ( $10^{5}$ fungal spores $\mathrm{mL}^{-1}$ ) of B. cinerea, C. acutatum and R. stolonifer suspensions under similar storage conditions. Positive results were characterised by the absence of fungal development.

\subsubsection{Grape Bioassays}

Treatments $(n=9)$ ), each having 10 replicates (containing 10 grape berries per jar), were evaluated for biocontrol efficacy assays which was performed on "Regal Seedless" table grapes (Vitis vinifera). Grapes were uniformly wounded (three wounds per spot) with a sterile needle $(<1 \mathrm{~mm}$ diameter per wound) and allowed to dry prior to yeast and fungal treatments. The wounded berries were sprayed with the yeast (C. pyralidae and P. kluyveri) cell suspension $\left(10^{8}\right.$ cell $\left.\mathrm{mL}^{-1}\right)$ until the dried wounds were filled with the suspension, and subsequently allowed to dry again for $30 \mathrm{~min}$. The dried berries were then sprayed separately with a fungal spore suspension $\left(10^{5}\right.$ spores $\left.\mathrm{mL}^{-1}\right)$. The negative controls (10 berries each) were prepared by spraying the fungal spores suspension on the wounded berries without prior yeast treatment. All grape treatments were maintained in sterilised, sealed jars at $-0.5^{\circ} \mathrm{C}$ for 4 weeks, and then incubated at $20^{\circ} \mathrm{C}$ for 7 days. The antagonistic properties of C. pyralidae and P. kluyveri were analysed visually by assessing the colour changes of the berries and fungal development. 


\subsection{Extraction and Gas Chromatographic Analyses of Volatile Compounds}

A volume $(10 \mathrm{~mL})$ of the crude biopreservation samples were placed in a $20 \mathrm{~mL}$ headspace vial to which $\mathrm{NaCl}(30 \% \mathrm{~m} / \mathrm{v})$ was added. Vials were spiked with $100 \mu \mathrm{L}$ of anisole $\mathrm{d}_{8}$ and 3-octanol as internal standards. SPME vials (Sigma-Aldrich, Darmstadt, Germany) were equilibrated for $5 \mathrm{~min}$ at $50{ }^{\circ} \mathrm{C}$ in the CTC autosampler incubator at $250 \mathrm{rpm}$. Subsequently, a $50 / 30 \mathrm{~m}$ divinylbenzene/-carboxen/-polydimethylsiloxane (DVB/CAR/PDMS) coated fibre was exposed to the sample headspace for $10 \mathrm{~min}$ at $50{ }^{\circ} \mathrm{C}$. After VOCs adsorption onto the fibre, desorption of the VOCs from the fibre coating was carried out in the injection port of the gas chromatography-mass spectrometry (GC-MS) for $10 \mathrm{~min}$. The fibre was inserted in a fibre conditioning station for $10 \mathrm{~min}$ between samples for cleaning to prevent cross- and carry-over contamination. Chromatographic separation of the VOCs was performed in a Thermo Trace 1310 gas chromatograph coupled with a Thermo TSQ 8000 mass spectrometer detector (Thermo Fisher Scientific, Vantaa, Finland). The GC-MS system was equipped with a polar DB-FFAP column (model number: J\&W 122-3263), with a nominal length of $60 \mathrm{~m}, 250 \mu \mathrm{m}$ internal diameter and $0.5 \mu \mathrm{m}$ film thickness. Analyses were determined using helium as a carrier gas at a flow rate of $2.9 \mathrm{~mL} \mathrm{~min}^{-1}$. The injector temperature was maintained at $250{ }^{\circ} \mathrm{C}$. The oven program was as follows: $350{ }^{\circ} \mathrm{C}$ for $17 \mathrm{~min}$, which was then ramped to a final temperature of $240{ }^{\circ} \mathrm{C}$ at a ramping rate of $12{ }^{\circ} \mathrm{C} \mathrm{min}{ }^{-1}$-a temperature that was constantly maintained for $6 \mathrm{~min}$. The mass selective detection (MSD) was operated in a full scan mode and both the ion source transfer line temperatures were maintained at $250{ }^{\circ} \mathrm{C}$. Compounds were tentatively identified by blasting against the mass spectral libraries (NIST, version 2.0, Gaithersburg, MD, USA).

\subsection{Statistical Analysis}

To determine whether there were significant differences within treatments, one-way analysis of variance (ANOVA) was performed using the general linear means procedure of SAS version 9.4 (SAS Institute Inc., Cary, NC, USA). Student's t least significant difference (LSD) values were calculated at the $5 \%$ probability level $(p=0.05)$ to facilitate comparison between treatment means. The significant difference was calculated at the $5 \%$ level and $p<0.05$ was considered significant for treatments.

\section{Results and Discussion}

\subsection{Production of Biopreservation Compounds and Their Effect on the Growth of Spoilage Yeasts}

The results in Figure 1 show that, using GPA as fermentation medium, C. pyralidae and P. kluyveri were able to secret crude extracellular compounds with growth inhibition activity against $D$. bruxellensis and Z. bailii, known spoilage yeasts in fruit-derived beverages. This was observed by the presence of clear zones of inhibition around the yeast colonies or agar wells. A visual observation of the clear zone of inhibition was required at this stage to verify the growth inhibition compound production and the presence of inhibition activity for the yeasts and their cell free supernatants (crude samples). Previous studies on inhibition assays were conducted using costly refined culturing media such as YPD $[28,43]$. However, the current study successfully managed to use a less expensive GPA for antimicrobial compound production. The findings in this work are complementary and in agreement with the research conducted by Mewa-Ngongang et al. [43]. These authors conducted a kinetic study and focused on the optimisation of biopreservation compound production using GP extract, and demonstrated that GP extract with a total sugar concentration of $150 \mathrm{~g} \mathrm{~L}^{-1}$ was a suitable medium for the production of antimicrobial compounds from C. pyralidae and P. kluyveri strains.

Biopreservation compound production was shown to be sugar-dependent and the best growth inhibition was observed at a sugar concentration of $150 \mathrm{~g} \mathrm{~L}^{-1}$, with the biggest volumetric zone of inhibition being $C$. pyralidae against $D$. bruxellensis (Figure 1c). Similar results were observed for the P. kluyveri strain against D. bruxellensis (results not shown). Further observations indicated shorter fermentation times and lower substrate concentration can be used to reduce operational costs while attaining the desired product. Although other yeast strains are known to have growth inhibition 
properties against $Z$. bailii this study reports on the growth inhibition properties of C. pyralidae and P. kluyveri against Z. bailii. Mehlomakulu et al. [43] only reported on the growth inhibition activity of $C$. pyralidae against $D$. bruxellensis. However, this study also showed $P$. kluyveri as an antagonistic microorganism against $D$. bruxellensis (Figure 1a), with further evidence showing C. pyralidae having growth inhibition activities against Z. bailii (Figure 1b); a profile indicating C. pyralidae has a much broader biocontrol application.

a

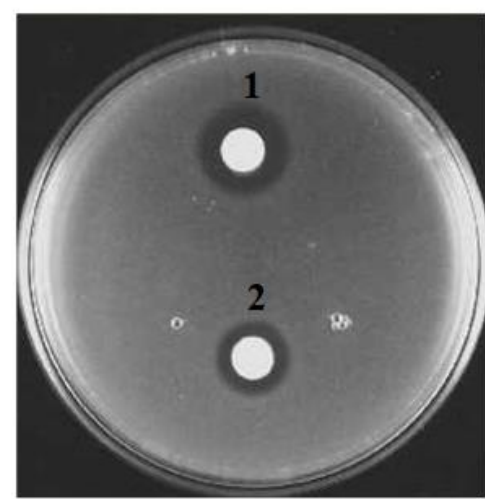

b

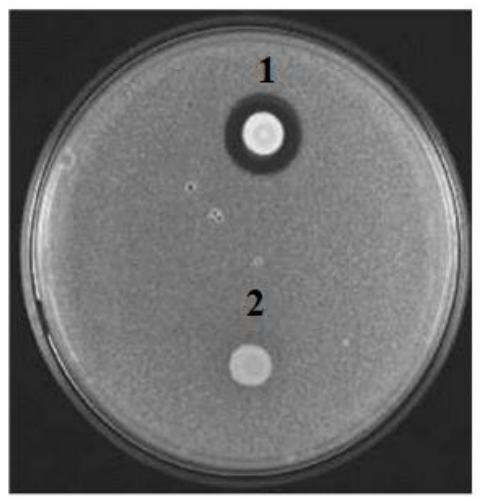

c

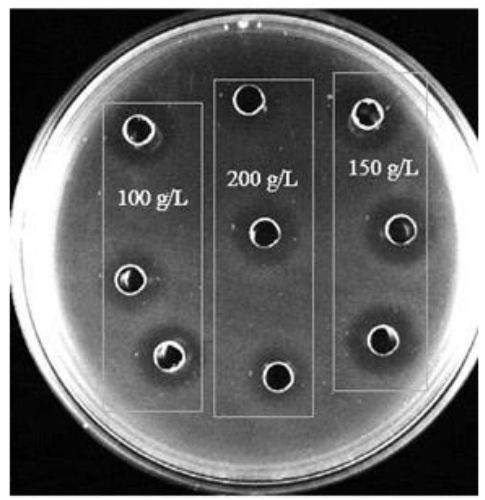

Figure 1. (a) Antagonistic activity of C. pyralidae (1) and P. kluyveri (2) against D. bruxellensis. (b) Antagonistic activity of C. pyralidae (1) and P. kluyveri (2) against Z. bailii. (c) Depiction of the inhibition activity of the biopreservation compounds produced by the antagonistic yeasts $C$. pyralidae against D. bruxellensis after $24 \mathrm{~h}$ of fermentation in grape pomace with varying sugar concentration (100, 150 and $\left.200 \mathrm{~g} \mathrm{~L}^{-1}\right)$.

\subsection{Effect of C. pyralidae and P. kluyveri Cells on Fungal Growth}

A radial inhibition assay was performed in order to assess the antagonistic effect of $C$. pyralidae and P. kluyveri on the germination of B. cinerea, C. acutatum and R. stolonifer spores. A $100 \%$ inhibition against the germination of $B$. cinerea, $C$. acutatum and $R$. stolonifer was observed on the low-cost GPA plates (Figure 2A), as indicated by similar FRI-values for the three different fungi (Figure 2B). It was evident that yeasts can prevent the growth of fungi in different ways, such as the ability to outgrow the spoilage fungi and to rapidly colonise surfaces, thereby reducing fungal development.

This is the first report on the growth inhibition properties of $C$. pyralidae and P. kluyveri against fruit spoilage fungi $C$. acutatum and R. stolonifer. However, this study also showed the potential of these yeast strains as biological control agents against $B$. cinerea. The antagonistic activity of yeast against fruit spoilage fungi was previously conducted albeit on refined culturing media $[27,38,48]$, but not on GPA plates as carried out in this work. The usefulness of GPA as a cheap and suitable medium for antagonistic activity was demonstrated in this study. 
A
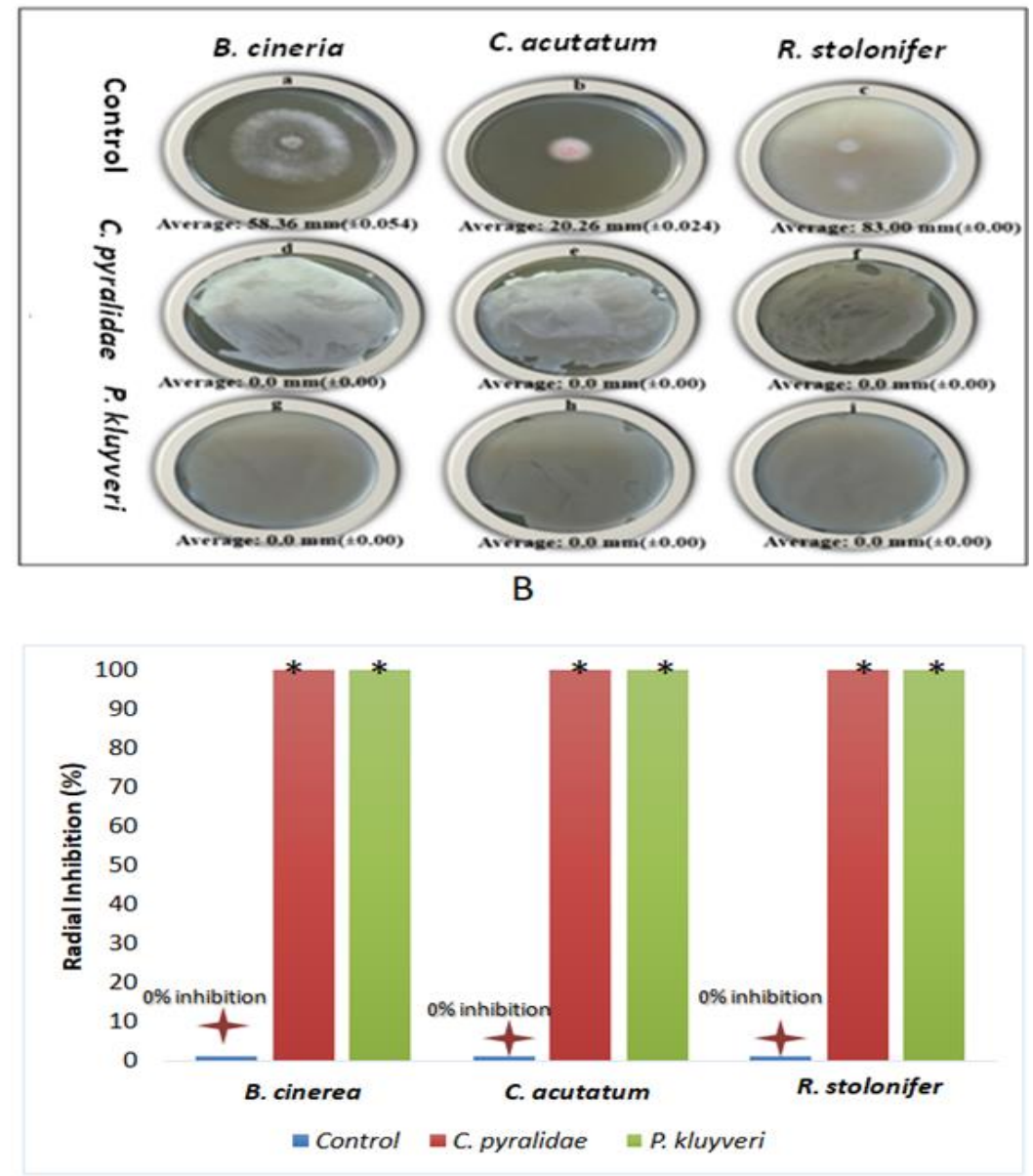

Figure 2. The visual (A) and graphical (B) representation the antagonistic effect of $C$. pyralidae cells on B. cinerea (A: d), C. acutatum (A: e) and R. stolonifer (A: f), and the antagonistic effects of Pichia kluyveri cells on the growth of B. cinerea (A: g), C. acutatum (A: h) and R. stolonifer (A: i). The negative controls are displayed as B. cinerea (A; a), C. acutatum (A: b) and R. stolonifera (A: c). Values are averages of three replicates per treatment with the standard deviation given in brackets. The asterisk $\left(^{*}\right)$ indicates values that differ significantly from the control $(p<0.05)$.

\subsection{Effect of Volatile Organic Compounds (VOCs) on Fungal Growth}

The influence of yeast-produced VOCs on fungal growth of fruit was investigated using a mouth to mouth assay. Compared to the negative controls, the visual (Figure 3A) and the graphical (Figure 3B) representation showed C. pyralidae and P. kluyveri producing VOCs that have an ability to completely inhibit the growth of B. cinerea, C. acutatum and R. stolonifer. Apart from the abovementioned cell antagonistic properties, the biocontrol mechanisms include the ability to secrete extracellular metabolites (e.g., VOCs) with growth inhibition activity against spoilage fungi $[39,40,49,50]$. The antagonistic effect of VOCs produced by Debaryomyces hansenii against Mucor circinelloides, Aspergillus sp., Fusarium proliferatum and F. subglutinans was also confirmed previously using the same mouth to mouth assay technique [48]. Contarino et al. 2019 [42] also reported the antagonistic mechanism of VOCs that was possibly coupled with the secretion of carbon dioxide in a closed packaging environment. Additionally, this study further demonstrated the potential of VOCs produced by C. pyralidae and $P$. kluyveri to inhibit the growth of B. cinerea, C. acutatum and R. stolonifer. The findings of the current study are vital in addressing fungal contamination in fruits and the derived beverages. As with many other yeast-related antagonistic studies [32,33,36,42], further investigation of the antagonistic mechanisms for C. pyralidae and P. kluyveri is recommended. 
$\mathbf{A}$

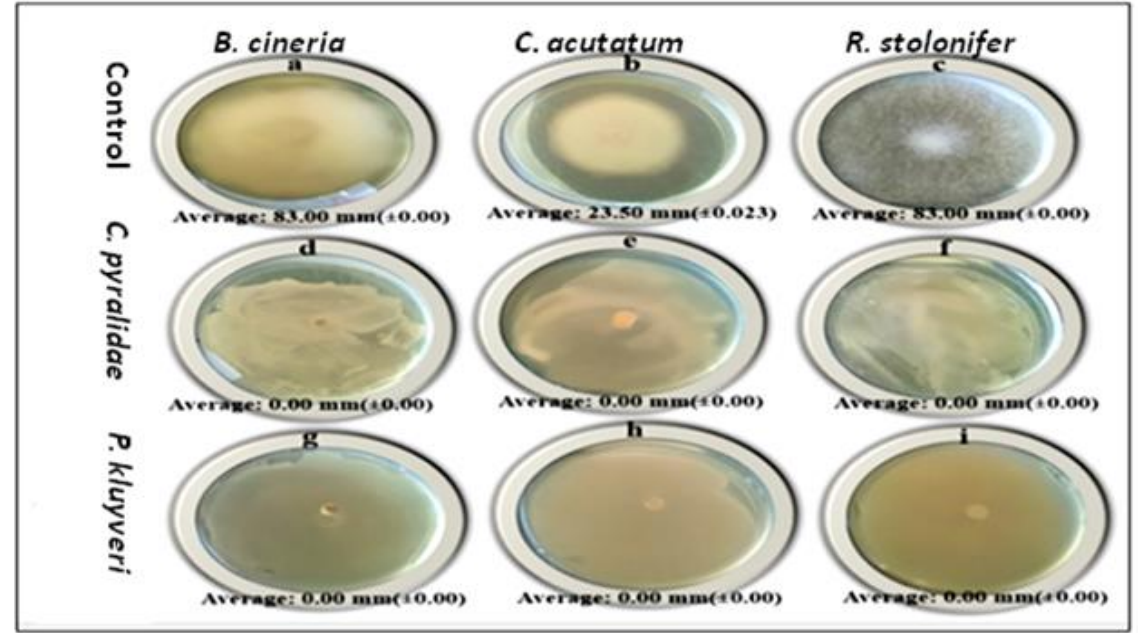

B

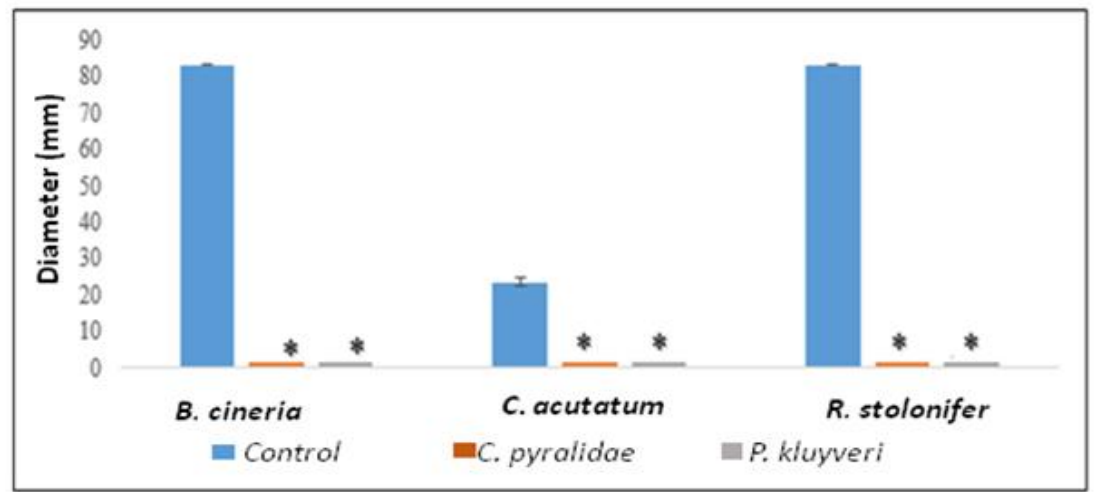

Figure 3. The visual (A) and graphical (B) representation the antagonistic effect of volatiles produced by C. pyralidae against B. cinerea (A: d), C. acutatum (A: e) and R. stolonifer (A: f), and the antagonistic effects of Pichia kluyveri against the growth of B. cinerea (A: d), C. acutatum (A: e) and R. stolonifer (A: f). The negative controls are displayed as B. cinerea (A: a), C. acutatum (A: b) and R. stolonifera (A: c). Values are averages of three replicates with the standard deviation given brackets. The asterisk $\left({ }^{*}\right)$ indicates values that differ significantly from the control $(p<0.05)$.

\subsection{Postharvest Control Efficacy of C. pyralidae and P. kluyveri on Fungal Growth}

\subsubsection{Apple Bioassay}

The evaluation of the efficacy of yeasts in preventing fungal spoilage of apples using bioassays showed a considerable decay reduction (Figure 4). For the purpose of visual representation, only three apples per treatment were selected as representatives (Figure 4). The apple bioassay demonstrated the ability of C. pyralidae and P. kluyveri to control spoilage caused by B. cinerea, C. acutatum and $R$. stolonifer; however, the inhibition responses were yeast and fungal species-dependent. Near complete (100\%) fungal growth inhibition was observed when both C. pyralidae and P. kluyveri were tested against $C$. acutatum. C. pyralidae, albeit only showing a 43 and $52 \%$ growth inhibition of $B$. cinerea and $R$. stolonifer, respectively, while $P$. kluyveri revealed a 38 and $22 \%$ growth inhibition of $B$. cinerea and $R$. stolonifer. Fluctuating in vivo postharvest control responses have been reported for other species including Sporidiobolus pararoseus [51], Saccharomyces cerevisiae, Wickerhamomyces anomalus, Metschnikowia pulcherrima and Aureobasidium pullulans [52] and Hanseniaspora uvarum [46]. Although C. pyralidae and P. kluyveri showed greater biocontrol potential on plate assays, the apple bioassay showed a significant decay reduction (Figure 4). These observations on apples could be of great 
importance in industry as these biocontrol yeasts can be further tested on patulin producing strains such as Penicillium expansum, which is currently a challenge in the beverage industry $[16,53]$.

A

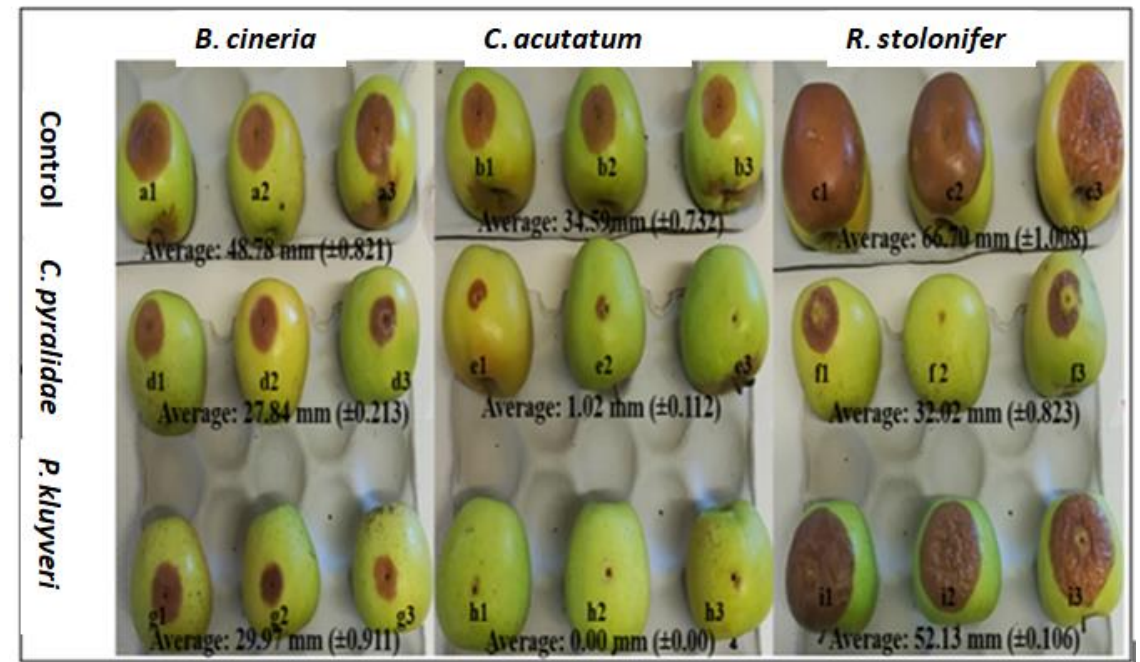

B

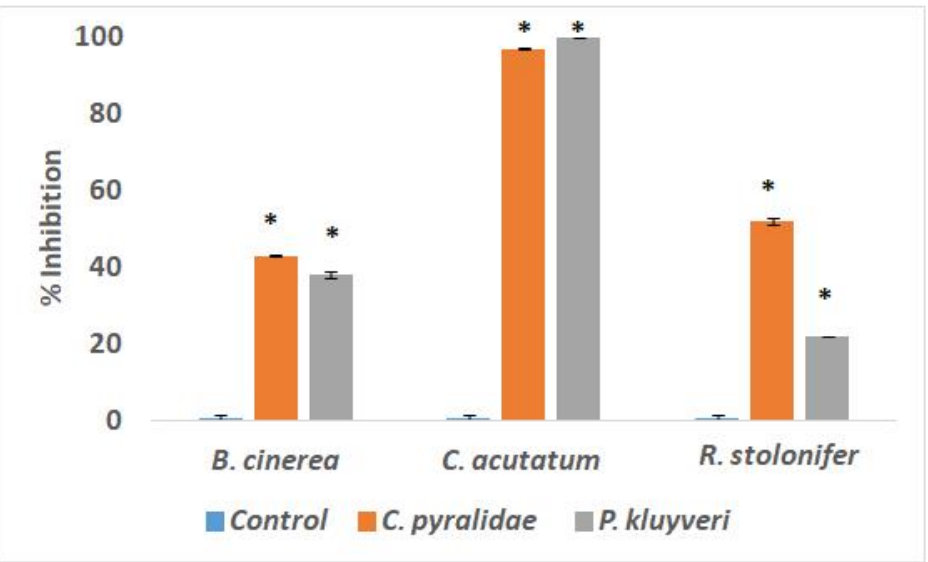

Figure 4. The visual (A) and graphical (B) representation of the apple bioassays for C. pyralidae against the growth of B. cinerea (A: d1-d3), C. acutatum (A: e1-e3) and R. stolonifer (A: f1-f3), and for P. kluyveri against the growth of B. cinerea (A: g1-g3), C. acutatum (A: h1-h3) and R. stolonifer (A: i1-i3). The negative controls are displayed as B. cinerea (A: a1-a3), C. acutatum (A: b1-b3) and R. stolonifera (A: c1-c3). Values are averages of 10 replicates per treatment with the standard deviation shown in brackets. The asterisk $\left({ }^{*}\right)$ indicates values that differ significantly from the control $(p<0.05)$.

\subsubsection{Grape Bioassays}

The grape bioassay under a closed airspace was carried out in order to assess the efficacy of the antagonistic effects of VOCs produced by C. pyralidae and P. kluyveri on table grapes, and to verify the results achieved during the in vitro assays (Figure 3). Unlike apple bioassays, grape spoilage is usually measured per bunch and not as individual berries. Therefore, the radial inhibition tests were deemed unnecessary. Interestingly, a 100\% inhibition of B. cinerea, C. acutatum and R. stolonifer growth was observed in vivo (Figure 5). Based on these observations, the biocontrol effect (in vivo) of VOCs from C. pyralidae and P. kluyveri was confirmed by $100 \%$ inhibition or $0 \%$ decay on grapes (sealed jar settings). This showed that the VOCs played a vital role in preventing fungal growth. Undoubtedly, the complete inhibition of fungal growth makes C. pyralidae and P. kluyveri suitable candidates for postharvest control and confirms the yeast's ability to produce VOCs with antimicrobial properties in sealed/tightly packaged fruit [51,54]. 


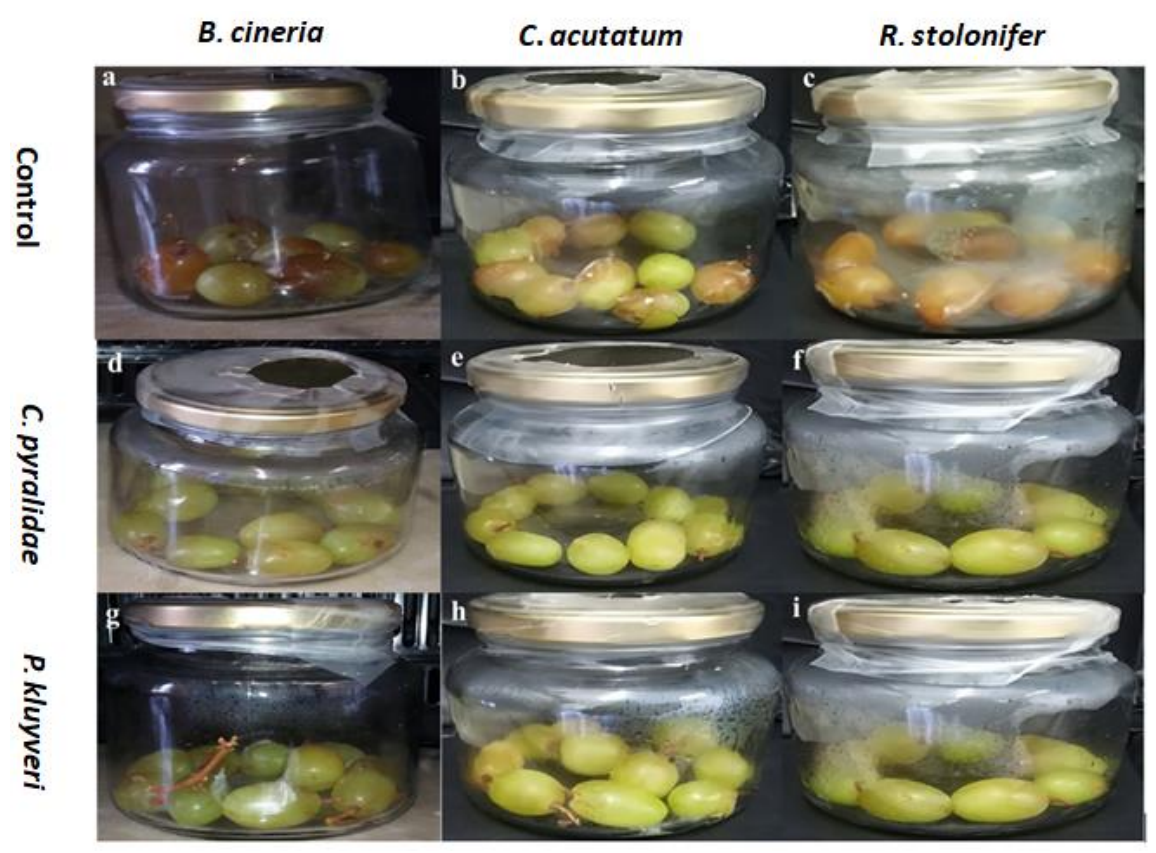

Figure 5. The antagonistic effect of volatiles produced by C. pyralidae against the growth of Botrytis cinerea (d), C. acutatum (e) and R. stolonifer (f), and the antagonistic effect of volatiles produced by Pichia kluyveri on B. cinerea (g), C. acutatum (h) and R. stolonifer in sealed jars. Negative controls are shown as B. cinerea (a), C. acutatum (b) and $R$. stolonifer (c). Ten replicates consisting of 10 grape berries per jar were tested. All berries in the negative control jars were spoiled $(0 \%$ inhibition \pm 0.00$)$ while the treated jars were not spoiled $(100 \%$ inhibition \pm 0.00$)$.

\subsection{Identification of the VOCs Produced by C. pyralidae and P. kluyveri}

VOCs $(n=25)$ were produced by each of the yeast and were identified and similar VOCs profiles were observed in both biocontrol yeast supernatants. These VOCs were isobutyl acetate, isobutanol, ethyl acetate, isoamyl acetate, limonene, isoamyl alcohol, ethyl caproate, hexyl acetate, acetoin, 4-hexen-1-ol, acetate, hexanol, nonanal, ethyl caprylate, acetic acid, trans-1-phenyl-1-butene, furfuryl acetate, 2-methyl-3-thiolanone, 4-methylbenzaldehyde, isobutyric acid, 3-(methylthio) propylacetate, ethyl dec-9-enoate, phenethyl acetate, 2,5-dimethylbenzaldehyde and 2-phenylethanol. Most of the identified compounds were esters, alcohols and fatty acids that are safely used in the food, beverages, pharmaceutical and the cosmetic industries [23]. In the context of natural biological control, the antagonistic action mechanisms of some yeasts have indeed been linked to the production of some VOCs from the category of alcohols, organic acids and esters including some of the identified VOCs are currently used as biocontrol agents in the food and beverage industries [38-40]. Growth inhibition properties of 2-phenylethanol [50,55], ethyl acetate [39] and acetic acid [40] have also been reported. Growth inhibition of spoilage fungi by VOCs have been linked to preventing mycelial growth and suppressing conidial germination [37].

Although the antagonistic effect of C. pyralidae and P. kluyveri is also related to the production of VOCs, it is not yet clear which of the aforementioned compounds, or combinations thereof, may be responsible for the growth inhibition activity. Hence, more research about these compounds still needs to be conducted.

\section{Conclusions}

The crude samples collected from fermentation broth inoculated with C. pyralidae or P. kluyveri showed can be used to control fruit derived beverage spoilage organisms $D$. bruxellensis, D. anomala and Z. bailii. Additionally, the cell suspensions of C. pyralidae and P. kluyveri showed growth inhibition properties against fruit spoilage fungi B. cinerea, C. acutatum and $R$. stolonifera, which is an important 
achievement for the alleviation of spoilage and also the mycotoxin burden faced by fruits-derived beverage producers. This study also showed that grape pomace extract can be used as a cost-effective renewable bioresource for the growth of biocontrol yeasts and production of biopreservation compounds. The potential of VOCs as a mechanism of inhibition was also shown. Future studies should investigate the mechanisms of inhibition of VOCs. Additional research is needed to determine the minimum inhibitory concentrations of individual VOCs as well as the evaluation of antimicrobial activity of pure and/or combinations of VOCs. Given the risks posed by patulin producing strain of Penicillium sp. on pome and stone fruits, further research should also focus on the efficacy assessments, the regulatory implications and food-safety aspects associated with the studied biological control yeasts.

Author Contributions: Conceptualization, M.M.-N., H.W.d.P.; Methodology and software, M.M.-N., S.K.O.N. and B.S.C.; Validation, S.K.O.N., H.W.d.P., B.S.C. and N.P.J.; Formal analysis, M.M.-N., L.M. and U.F.H.; Investigation, M.M.-N. and U.F.H.; Resources, N.P.J., H.W.d.P. and S.K.O.N.; Data curation, B.S.C., M.M.-N. and L.M.; Writing—original draft preparation, M.M.-N.; Visualization, review and editing, S.K.O.N., H.W.d.P., N.P.J., B.S.C., L.M. and U.F.H.; Supervision, S.K.O.N., H.W.d.P. and N.P.J.; Project administration, N.P.J., H.W.d.P. and S.K.O.N.; Funding acquisition, N.P.J., H.W.d.P. and S.K.O.N.

Funding: The financial support was provided by the National Research Foundation (NRF) and the Agricultural Research Council (ARC) of South Africa.

Acknowledgments: The authors would like to thank the Agricultural Research Council, the National Research Foundation (NRF) and the Bioresource Engineering Research Group (BioERG), Department of Biotechnology, Cape Peninsula University of Technology for funding and infrastructure. The authors thank all students, interns, technicians and research assistants for their contribution.

Conflicts of Interest: The authors hereby declare that they have no conflict of interest.

\section{References}

1. Parveen, S.; Wani, A.H.; Bhat, M.Y.; Koka, J.A.; Wani, F.A. Management of postharvest fungal rot of peach (Prunus persica) caused by Rhizopus stolonifer in Kashmir Valley, India. Plant Pathol. Quar. 2016, 6, 19-29. [CrossRef]

2. Salman, M.A.M. Biological Control of Rhizopus Soft Rot on Apple, Pear and Peach by Trichoderma harzianum. Ph.D. Thesis, An-Najah National University, Nablus, State of Palestine, 14 December 2005.

3. Powelson, E. Initiation of Strawberry fruit rot caused by Botrytis cinerea. Phytopathology 1960, 50, 491-494.

4. Pearson, R.C.; Goheen, A.C. Compendium of Grape Diseases; APS Press: St Paul, MN, USA, 1988; pp. 13-15.

5. Romanazzi, G.; Smilanick, J.L.; Feliziani, E.; Droby, S. Integrated management of postharvest gray mold on fruit crops. Postharvest Biol. Technol. 2016, 113, 69-76. [CrossRef]

6. Tyagi, S.; Sahay, S.; Imran, M.; Rashmi, K.; Mahesh, S.S. Pre-harvest factors influencing the postharvest quality of fruits: A review. Curr. J. Appl. Sci. Technol. 2017, 23,1-12. [CrossRef]

7. Droby, S. Improving quality and safety of fresh fruits and vegetables after harvest by the use of biocontrol agents and natural materials. In Proceedings of the I International Symposium on Natural Preservatives in Food Systems, Princeton, NJ, USA, 30-31 March 2005; pp. 45-52.

8. El Ghaouth, A.; Wilson, C.; Wisniewski, M. Biologically-based alternatives to synthetic fungicides for the control of postharvest diseases of fruit and vegetables. In Diseases of Fruits and Vegetables: Volume II; Naqvi, S.A.M.H., Ed.; Springer: Berlin/Heidelberg, Germany, 2004; pp. 511-535.

9. Singh, D.; Sharma, R.R. Postharvest Diseases of Fruit and Vegetables and Their Management; Daya Publishing House: New Delhi, India, 2007.

10. Zhu, S.J. Non-chemical approaches to decay control in postharvest fruit. In Advances in Postharvest Technologies for Horticultural Crops; Noureddine, B., Norio, S., Eds.; Research Signpost: Trivandrum, India, 2006; pp. 297-313.

11. Sharma, R.R.; Singh, D.; Singh, R. Biological control of postharvest diseases of fruits and vegetables by microbial antagonists: A review. Biol. Control 2009, 50, 205-221. [CrossRef]

12. Williamson, B.; Tudzynski, B.; Tudzynski, P.; van Kan, J.A. Botrytis cinerea: The cause of grey mould disease. Mol. Plant Pathol. 2007, 8, 561-580. [CrossRef] [PubMed] 
13. Frisvad, J.C.; Thrane, U.; Samson, R.A.; Pitt, J.I. Important mycotoxins and the fungi which produce them. In Advances in Food Mycology; Hocking, A.D., Pitt, J.I., Samson, R.A., Thrane, U., Eds.; Springer: Berlin/Heidelberg, Germany, 2006; pp. 3-31.

14. Berthiller, F.; Crews, C.; Dall'Asta, C.; Saeger, S.D.; Haesaert, G.; Karlovsky, P.; Oswald, I.P.; Seefelder, W.; Speijers, G.; Stroka, J. Masked mycotoxins: A review. Mol. Nutr. Food Res. 2013, 57, 165-186. [CrossRef] [PubMed]

15. O’Brien, M.; Nielsen, K.F.; O'Kiely, P.; Forristal, P.D.; Fuller, H.T.; Frisvad, J.C. Mycotoxins and other secondary metabolites produced in vitro by Penicillium paneum Frisvad and Penicillium roqueforti Thom isolated from baled grass silage in Ireland. J. Agric. Food Chem. 2006, 54, 9268-9276. [CrossRef]

16. Tannous, J.; Keller, N.P.; Atoui, A.; El Khoury, A.; Lteif, R.; Oswald, I.P.; Puel, O. Secondary metabolism in Penicillium expansum: Emphasis on recent advances in patulin research. Crit. Rev. Food Sci. Nutr. 2018, 58, 2082-2098. [CrossRef]

17. Saxena, N.; Dwivedi, P.D.; Ansari, K.M.; Das, M. Patulin in apple juices: Incidence and likely intake in an Indian population. Food Addit. Contam. 2008, 1, 140-146. [CrossRef]

18. Zaied, C.; Abid, S.; Hlel, W.; Bacha, H. Occurrence of patulin in apple-based-foods largely consumed in Tunisia. Food Control 2013, 31, 263-267. [CrossRef]

19. Forouzan, S.; Madadlou, A. Incidence of patulin in apple juices produced in West Azerbayjan Province, Iran. J. Agric. Sci. Technol. 2014, 16, 1613-1622.

20. Comitini, F.; Di Pietro, N.; Zacchi, L.; Mannazzu, I.; Ciani, M. Kluyveromyces phaffii killer toxin active against wine spoilage yeasts: Purification and characterization. Microbiology 2004, 150, 2535-2541. [CrossRef]

21. Thomas, D.S.; Davenport, R.R. Zygosaccharomyces bailii-A profile of characteristics and spoilage activities. Food Microbiol. 1985, 2, 157-169. [CrossRef]

22. Zuehlke, J.M.; Petrova, B.; Edwards, C.G. Advances in the control of wine spoilage by Zygosaccharomyces and Dekkera/Brettanomyces. Annu. Rev. Food Sci. Technol. 2013, 4, 57-78. [CrossRef]

23. Cheetham, P.S. Combining the technical push and the business pull for natural flavours. In Biotechnology of Aroma Compounds; Berger, R.G., Ed.; Springer: Berlin/Heidelberg, Germany, 1997; pp. 1-49.

24. Mostafa, A.A.; Al-Askar, A.A.; Almaary, K.S.; Dawoud, T.M.; Sholkamy, E.N.; Bakri, M.M. Antimicrobial activity of some plant extracts against bacterial strains causing food poisoning diseases. Saudi J. Biol. Sci. 2018, 25, 361-366. [CrossRef] [PubMed]

25. Siroli, L.; Patrignani, F.; Serrazanetti, D.I.; Gardini, F.; Lanciotti, R. Innovative strategies based on the use of bio-control agents to improve the safety, shelf-life and quality of minimally processed fruits and vegetables. Trends Food Sci. Technol. 2015, 46, 302-310. [CrossRef]

26. Aloui, H.; Licciardello, F.; Khwaldia, K.; Hamdi, M.; Restuccia, C. Physical properties and antifungal activity of bioactive films containing Wickerhamomyces anomalus killer yeast and their application for preservation of oranges and control of postharvest green mold caused by Penicillium digitatum. Int. J. Food Microbiol. 2015, 200, 22-30. [CrossRef]

27. Cordero-Bueso, G.; Mangieri, N.; Maghradze, D.; Foschino, R.; Valdetara, F.; Cantoral, J.M.; Vigentini, I. Wild grape-associated yeasts as promising biocontrol agents against Vitis vinifera fungal pathogens. Front. Microbiol. 2017, 8, 2025. [CrossRef]

28. Mewa-Ngongang, M.; du Plessis, H.W.; Hutchinson, U.F.; Mekuto, L.; Ntwampe, S.K. Kinetic modelling and optimisation of antimicrobial compound production by Candida pyralidae KU736785 for control of Candida guilliermondii. Food Sci. Technol. Int. 2017, 23, 358-370. [CrossRef]

29. Bencheqroun, S.K.; Bajji, M.; Massart, S.; Labhilili, M.; El Jaafari, S.; Jijakli, M.H. In vitro and in situ study of postharvest apple blue mold biocontrol by Aureobasidium pullulans: Evidence for the involvement of competition for nutrients. Postharvest Biol. Technol. 2007, 46, 128-135. [CrossRef]

30. Liu, J.; Sui, Y.; Wisniewski, M.; Droby, S.; Liu, Y. Review: Utilization of antagonistic yeasts to manage postharvest fungal diseases of fruit. Int. J. Food Microbiol. 2013, 167, 153-160. [CrossRef] [PubMed]

31. Droby, S.; Vinokur, V.; Weiss, B.; Cohen, L.; Daus, A.; Goldschmidt, E.E.; Porat, R. Induction of resistance to Penicillium digitatum in grapefruit by the yeast biocontrol agent Candida oleophila. Phytopathology 2002, 92, 393-399. [CrossRef]

32. Spadaro, D.; Vola, R.; Piano, S.; Gullino, M.L. Mechanisms of action and efficacy of four isolates of the yeast Metschnikowia pulcherrima active against postharvest pathogens on apples. Postharvest Biol. Technol. 2002, 24, 123-134. [CrossRef] 
33. Spadaro, D.; Droby, S. Development of biocontrol products for postharvest diseases of fruit: The importance of elucidating the mechanisms of action of yeast antagonists. Trends Food Sci. Technol. 2016, 47, 39-49. [CrossRef]

34. Fan, Q.; Tian, S.; Liu, H.; Xu, Y. Production of $\beta$-1, 3-glucanase and chitinase of two biocontrol agents and their possible modes of action. Chin. Sci. Bull. 2002, 47, 292. [CrossRef]

35. Grevesse, C.; Lepoivre, P.; Jijakli, M.H. Characterization of the exoglucanase-encoding gene PaEXG2 and study of its role in the biocontrol activity of Pichia anomala strain K. Phytopathology 2003, 93, 1145-1152. [CrossRef] [PubMed]

36. Zhou, Y.; Li, W.; Zeng, J.; Shao, Y. Mechanisms of action of the yeast Debaryomyces nepalensis for control of the pathogen Colletotrichum gloeosporioides in mango fruit. Biol. Control 2018, 123, 111-119. [CrossRef]

37. Zheng, X.D.; Zhang, H.Y.; Sun, P. Biological control of postharvest green mold decay of oranges by Rhodotorula glutinis. Eur. Food Res. Technol. 2005, 220, 353-357. [CrossRef]

38. Grzegorczyk, M.; Żarowska, B.; Restuccia, C.; Cirvilleri, G. Postharvest biocontrol ability of killer yeasts against Monilinia fructigena and Monilinia fructicola on stone fruit. Food Microbiol. 2017, 61, 93-101. [CrossRef] [PubMed]

39. Hua, S.S.T.; Beck, J.J.; Sarreal, S.B.L.; Gee, W. The major volatile compound 2-phenylethanol from the biocontrol yeast, Pichia anomala, inhibits growth and expression of aflatoxin biosynthetic genes of Aspergillus flavus. Mycotoxin Res. 2014, 30, 71-78. [CrossRef] [PubMed]

40. Huang, R.; Li, G.Q.; Zhang, J.; Yang, L.; Che, H.J.; Jiang, D.H.; Huang, H.C. Control of postharvest Botrytis fruit rot of strawberry by volatile organic compounds of Candida intermedia. Phytopathology 2011, 101, 859-869. [CrossRef] [PubMed]

41. Lutz, M.C.; Lopes, C.A.; Rodriguez, M.E.; Sosa, M.C.; Sangorrín, M.P. Efficacy and putative mode of action of native and commercial antagonistic yeasts against postharvest pathogens of pear. Int. J. Food Microbiol. 2013, 164, 166-172. [CrossRef] [PubMed]

42. Contarino, R.; Brighina, S.; Fallico, B.; Cirvilleri, G.; Parafati, L.; Restuccia, C. Volatile organic compounds (VOCs) produced by biocontrol yeasts. Food Microbiol. 2019, 82, 70-74. [CrossRef] [PubMed]

43. Mehlomakulu, N.N.; Setati, M.E.; Divol, B. Characterization of novel killer toxins secreted by wine-related non-Saccharomyces yeasts and their action on Brettanomyces spp. Int. J. Food Microbiol. 2014, 188, 83-91. [CrossRef] [PubMed]

44. Crafack, M.; Mikkelsen, M.B.; Saerens, S.; Knudsen, M.; Blennow, A.; Lowor, S.; Takrama, J.; Swiegers, J.H.; Petersen, G.B.; Heimdal, H. Influencing cocoa flavour using Pichia kluyveri and Kluyveromyces marxianus in a defined mixed starter culture for cocoa fermentation. Int. J. Food Microbiol. 2013, 167, 103-116. [CrossRef]

45. Gross, S.; Kunz, L.; Müller, D.C.; Santos Kron, A.; Freimoser, F.M. Characterization of antagonistic yeasts for biocontrol applications on apples or in soil by quantitative analyses of synthetic yeast communities. Yeast 2018, 35, 559-566. [CrossRef]

46. Qin, X.; Xiao, H.; Xue, C.; Yu, Z.; Yang, R.; Cai, Z.; Si, L. Biocontrol of gray mold in grapes with the yeast Hanseniaspora uvarum alone and in combination with salicylic acid or sodium bicarbonate. Postharvest Biol. Technol. 2015, 100, 160-167. [CrossRef]

47. Núñez, F.; Lara, M.S.; Peromingo, B.; Delgado, J.; Sánchez-Montero, L.; Andrade, M.J. Selection and evaluation of Debaryomyces hansenii isolates as potential bioprotective agents against toxigenic penicillia in dry-fermented sausages. Food Microbiol. 2015, 46, 114-120. [CrossRef]

48. Medina-Córdova, N.; López-Aguilar, R.; Ascencio, F.; Castellanos, T.; Campa-Córdova, A.I.; Angulo, C. Biocontrol activity of the marine yeast Debaryomyces hansenii against phytopathogenic fungi and its ability to inhibit mycotoxins production in maize grain (Zea mays L.). Biol. Control 2016, 97, 70-79. [CrossRef]

49. Mewa-Ngongang, M.; du Plessis, H.W.; Ntwampe, S.K.; Chidi, B.S.; Hutchinson, U.F.; Mekuto, L.; Jolly, N.P. Grape Pomace Extracts as Fermentation Medium for the Production of Potential Biopreservation Compounds. Foods 2019, 8, 51. [CrossRef] [PubMed]

50. Druvefors, U.Ä.; Passoth, V.; Schnürer, J. Nutrient effects on biocontrol of Penicillium roqueforti by Pichia anomala J121 during airtight storage of wheat. Appl. Environ. Microbiol. 2005, 71, 1865-1869. [CrossRef] [PubMed]

51. Huang, R.; Che, H.J.; Zhang, J.; Yang, L.; Jiang, D.H.; Li, G.Q. Evaluation of Sporidiobolus pararoseus strain YCXT3 as biocontrol agent of Botrytis cinerea on post-harvest strawberry fruits. Biol. Control 2012, 62, 53-63. [CrossRef] 
52. Parafati, L.; Vitale, A.; Restuccia, C.; Cirvilleri, G. Biocontrol ability and action mechanism of food-isolated yeast strains against Botrytis cinerea causing post-harvest bunch rot of table grape. Food Microbiol. 2015, 47, 85-92. [CrossRef] [PubMed]

53. Chen, L.; Ingham, B.H.; Ingham, S.C. Survival of Penicillium expansum and patulin production on stored apples after wash treatments. J. Food Sci. 2004, 69, C669-C675. [CrossRef]

54. Li, Q.; Ning, P.; Zheng, L.; Huang, J.; Li, G.; Hsiang, T. Effects of volatile substances of Streptomyces globisporus JK-1 on control of Botrytis cinerea on tomato fruit. Biol. Control 2012, 61, 113-120. [CrossRef]

55. Fredlund, E.; Blank, L.M.; Schnürer, J.; Sauer, U.; Passoth, V. Oxygen-and glucose-dependent regulation of central carbon metabolism in Pichia anomala. Appl. Environ. Microbiol. 2004, 70, 5905-5911. [CrossRef] [PubMed]

(C) 2019 by the authors. Licensee MDPI, Basel, Switzerland. This article is an open access article distributed under the terms and conditions of the Creative Commons Attribution (CC BY) license (http://creativecommons.org/licenses/by/4.0/). 